with chloroform vapour. Spasma glottidis, resistance, general rigidity or struggling, spasm of the respiratory muscles and diaphragm, together with spasm of the myocardium,- these are all provoked in rarious degrees, sequences, and combinations by the inspiration of surcharged air. The patients die from asphyxia more or less complicated by an angina which affects the heart much as cramp affects the calf of the leg. If the patients do not die suddenly as above and the chloroform be pushed there comes a paraly tic relaxation of the glottis-as in drowning-and this is followed by further deep inspirations of surcharged air, just as, in some fatal cases of drowning, water and mud are drawn into the lungs. It is well known to practical men who have seen much of drowning cases that there are some cases brought to bank with the heart still beating and the chest movements still going, but which cannot be resuscitated, work as hard as we may at artificial respiration. They are these particular cases, and at the necropsy mud and water are found in the bronchial tubes. When got out of the water these cases can be distinguished by the fact that, though still breathing, foam issues from the mouth and nose. In my experience those cases are rarely resuscitated. Now in chloroform poisoning, after the paralytic relaxation of the glottis, the surcharged air re-enters the bronchi, surcharges afresh the pulmo-cardiac blood, and fills up the recesses of the air passages. Here the end organs of the whole system of respiratory nerves are poisoned by direct local soakage, while the surcharged pulmonary blood, passing on successively through the left chambers of the heart, poisons the myocardium and its local nerves in the same way. All this may be the work of half a minute in cases where chloroform is "pushed" after resistance has been provoked. If time had been given for the diffusion throughout the system of the chloroform ingested it would not even have produced anæsthesia. But it kills because it surcharges the local blood of the lungs and heart. It is not the total quantity ingested, it is the local surcharge-the concentrated action. A minim of oil of vitriol diffused through a wineglassful of water is drunk as a pleasant beverage a minim of oil of vitriol dropped into the glottis is fatal. Then, as the lungs have had their air passages re-filled with surcharged air, the local poisoning gces on long after the inhaler has been removed, and the blood current through the chambers of the heart continues to be surcharged long enough to kill. Snow showed that 18 minims in the blood of an average man spell full surgical anrsthesia and that 32 minims spell death. But it is probable that four minims injected into the pulmonary vein would $k i l l$ the heart nerves irretrievably. Powerfully absorbent must be the two successive chambers of the heart with all their complications of surface, in relation to blood which that organ has to receive from the lungs and to transmit under pressure to the general system. The experiment is one that could easily be tried at any slaughter-house or knacker's yard. What we want to know is what percentage of vapour-volume of chloroform serves to kill the animal heart beyond resuscitation. Waller has shown us that below 5 per cent. vapour-volume of chloroform in air arrests absolutely the function of a nerre, but not so as to prevent resuscitation. 6 per cent. kills the nerve. Now four minims of liquid chloroform may be regarded as four cubic inches of chloroform vapour. For a 6 per cent. charge this four cubic inches of chloroform vapour would saturate the entire mass of the pulmo-cardiac blood and myocardium tissues. Hence these chloroform cases, like those particular drowning cases, are irretrierable by artificial respiration. The myocardium has been killed.

Keferring to the injection of chloroform into the bloodvessels $I$ am not unmindful of the fact that this was done under the Hyderabad Commission. But the Hyderabad report on that point is badly given and the results are inconclusive. Moreover. those injections were made into the jugular vein after the vein had been tied. Now, tying the jugular vein would stop the current through that vein, and it is not safe to surmise as to how much of that chloroform arrived in the heart or how long it required for such chloroform to arrive. Again, such chloroform as did arrive in the heart would go into its right side. Now, the right heart has always been accustomed to contact with blood charged with carbon dioxide, whereas the left heart has always contained pure oxygenated blood. The result, therefore, of the contact of chloroform with the different sides of the heart may be as different as the results of the presence of urine in the urinary bladder or in the peritoneum.
In using the improved Krohne inhaler it can be demonstrated that a full manual compression of the bellows projects four cubic inches of air saturated with chloroform vapour into the mask, which I have called the mixing-box. Taking this as giving one cubic inch of chloroform vapour, and assuming that the on-coming inspiration draws 25 cubic inches of air through the mixing-box, we have 1 in 25 , or 4 per cent., for the vapour volume of chloroform in the inspired air. If one full manual compression be given into the ebb tide of each expiration (as described in my letters in THE LANCET of Sept. 30th (p. 922) and Oct. 28th (p. 1205), 1899) it follows that in one minute the patient will have received the vapour of some 20 minims of liquid chloroform into his lungs. Some of this 20 minims will have been exhaled by the lungs and skin, and as it requires 18 minims in the blood to induce full surgical anæsthesia this generalised effect will not be reached. But the ingested chloroform is probably a lethal dose by reason of the want of time for diffusion through the general system and the local surcharging of the pulmo-cardiac blood. For that reason a much smaller injection for each inspiration is directed, and from the commencement of the administration to the induction of full surgical anæsthesia about six minutes is best as the least period.

The perfectly safe exhibition of chloroform is to be attained by beginning with small volumes of cbloroform air for each inspiration, such as provoke neither cough nor resistance - certainly no spasm of the glottis. Here I differ somewhat from the text of the directions given by Dr. Clayton Lane, inasmuch as while I watch closely the phenomena of the anæsthesia I also cause myself to know where I am by regulation of the amount of chloroformed air injected for each inspiration. I thus use the two guidesobservation and dead-reckoning-and I make the featherindicator my index for the respiratory currents.

Manchester-square, $\mathrm{W}$.

\section{THE USE AND ABUSE OF PRESERVATIVES.}

By SAMUEL RIDEAL, D.SC. LOND., F.I.C.

THERE are two or three points arising out of the recent papers which have appeared in THE LANCET which some experiments of mine, conducted during the last six months, seem to throw some light upon. When I was fortunate enough to secure the coopperation of Mr. A. G. R. Foulerton at the end of 1898 for investigating this problem in $m y$ laboratory I realised that it was of a twofold character, and in the paper published in Public Health in May last by us we expressed our opinions (1) as to the quantities of preservatives necessary for preserving milk, and (2) the possibility of such quantities having injurious effects upon the consumer. In that paper we promised to extend our investigations, and as circumstances arose which necessitated our working in separate laboratories Mr. Foulerton continued the investigation into the second branch of the subject whilst I have recently confined my attention to the former. At the same time $I$ should like to take this opportunity of saying that I fully agree with Mr. Foulerton in the conclusions which he has drawn in the very able papers published in The LANCET of Nov. 25th (p. 1427) and Dec. 9th (p. 1577) 1899.

A good deal of the work which has recently been done on this subject has assumed the possibility of comparaticely large quantities of preservative material being present in the food-supply, and there seems to be some hesitation in accepting the proposition which $\mathrm{Mr}$. Foulerton and myself advanced in the paper above referred to- $-1 \mathrm{iz}$, that 1 part in 2000 of boric acid mixture and 1 in 50,000 of formal dehyde were quantities of preservatives sufficient for keeping milk sweet for a period of 24 hours even in warm weather. It is well known that at the present time these quantities are frequently exceeded, but I have been unable to find any experiments on a sufficiently large scale to warrant my believing that the milk trade necessitates higher quantities of these preservatives being added. I am assuming that the Departmental Committee at present dealing with this question will make it compulsory for the 
presence of any preservative in milk to be declared at the time of purchase, as I think that there is now a consensus of opinion that it is highly desirable that in special cases, such as in the case of invalids, it should be possible for the consumer to obtain a milk free from preservative, and that in all cases it is only fair that the consumer should be aware of the preservative if present. The views of Mr. Foulerton and myself as to the effect upon the health of adults and children of the above quantities of preservatives have already been stated in the paper referred to, and I need not go further into this matter, but the advisability of allowing greater amounts of preservatives than those mentioned to be present in "declared" milk is determined by the question whether the larger quantities are necessary for trade purposes. This point, of course, depends largely upon what is understood as "sour milk" by the consumer and this must obviously depend upon the acidity of the milk expressed in terms of lactic acid. In the following table I summarise the results obtained in a series of experiments undertaken to ascertain this point. Quantities of fresh milk containing (1) 1 in 2000 of boric acid, (2) 1 in 50,000 of formaldehyde, and (3) a control, were measured into balloon flasks and loosely plugged with cotton-wool. These sets were then incubated at the following temperatures: $13^{\circ} \mathrm{C}$, $18^{\circ} \mathrm{C}$, and $24^{\circ} \mathrm{C}$. (as representing approximately winter, medium, and summer temperatures); and 25 cubic centimetres were taken out from each and titrated every few hours with decinormal soda, using phenol-phthalein as an indicator, the total acidity being calculated to lactic acid (one cubic centimetre $\mathrm{N} / 10$ soda $=0.009$ gramme of lactic acid). The original milk at starting required five cubic centimetres $\mathrm{N} / 10$ soda per 25 cubic centimetres, corresponding to 0.18 per cent. of lactic acid.

\section{Table I.}

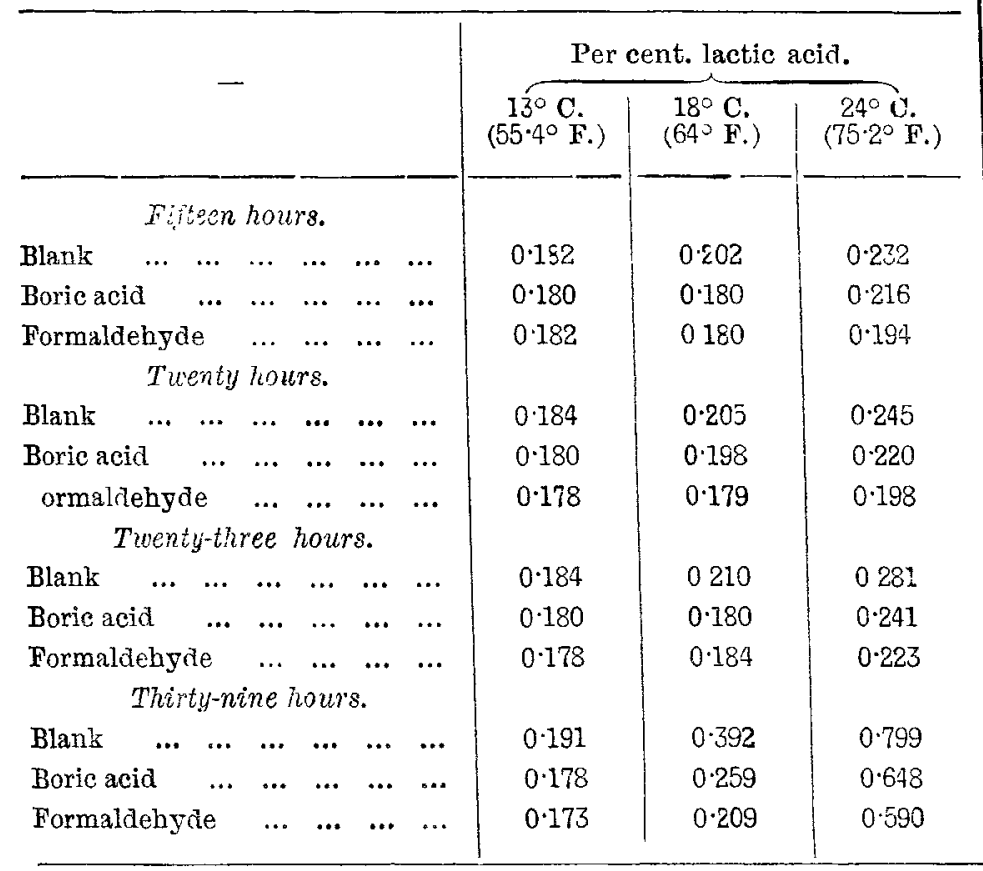

From these results it will be noticed that at the lowest temperature-viz, $13^{\circ} \mathrm{C}$.-even after 39 hours there is no increase in the asidity of the milk containing boric acid and formaldehyde, the actual titration recording a slightly lower amount of lactic acid. (The possible experimental error in these figures amount to \pm 0.007 per cent. of lactic acid.) In these two milks at $18^{\circ} \mathrm{C}$. there is no appreciable rise in the acidity till after 23 hours' incubation, whilst the unpreserved milk shows a gain of about 15 per cent. In considering the results at $24^{\circ} \mathrm{O}$. the question arises as to what maximum acidity can be allowed to milk without its being pronounced sour.

Thorner ${ }^{1}$ has investigated the acidity requisite to coagulate milk. Titrating under similar conditions to the above he found that milk coagulated on warming when the acidity reached $23^{\circ}$ (cubic centimetres $N / 10$ soda per 100 cubic centimetres of milk), corresponding to 0.207 per cent. of lactic acid. I have found the coagulating point somewhat higher than this. Normal milk was incubated at $22^{\circ} \mathrm{C}$. and every few hours a fraction was removed and tested by heating to $100^{\circ} \mathrm{C}$. for five minutes and also by pouring some of the

1 Chemische Zeitschrift, 1891, p. 1108. milk into boiling water, the acidity being determined at the same time.

TABLE II.

\begin{tabular}{c|c|c|c}
$\begin{array}{c}\text { No. of } \\
\text { hours. }\end{array}$ & $\begin{array}{c}\text { Degree of } \\
\text { acldity. }\end{array}$ & $\begin{array}{c}\text { Per cent. of } \\
\text { lactic acid. }\end{array}$ & Coagulation tests. \\
\hline 1 & 18.0 & 0.162 & Both tests negative. \\
4 & 19.0 & 0.171 & Ditto. \\
6 & 19.2 & 0.173 & Ditto. \\
8 & 19.6 & 0.176 & Ditto. \\
11 & 20.4 & 0.184 & Ditto. \\
15 & 28.0 & 0.252 & $\begin{array}{c}\text { Coagulated at 100 C., but } \\
\text { not by pouring inco hot } \\
\text { water. }\end{array}$ \\
\hline
\end{tabular}

Therefore, when the acidity exceeds 025 per cent. lactic acid the milk would be considered sour and unfit for sale, and taking this as the maximum acidity allowable it will be seen from Table 1 . that in all cases the milk has been kept sweet by the 1 in 2000 of boric acid and 1 in 50,000 of fcrmaldehyde for over 23 hours. In repeating this experiment with a milk incubated at $18^{\circ} \mathrm{O}$. it was found that when the acidity was equal to $25.6^{\circ}$, or 0.230 per cent. of lactic acid, the milk was sufficiently acid to cause a slight coagulation on heating on the water-bath. It will therefore be seen that Thorner's limit of 0.207 per cent. of lactic acid is rather too low and that from 0.23 to 0.25 per cent. of lactic acid is the limit which may be regarded as safe for dietetic purposes. Even if Thorner's limit of 0.207 per cent. of lactic acid be taken it will be seen that the quantity of boric acid and formaldebyde suggested are ample for keeping a milk sweet for 23 hours at $18^{\circ} \mathrm{C}$. But the quantity of boric acid is insufficient for keeping it sweet for a longer period than 15 hours, and of formaldehyde for a longer period than 20 hours, when the temperature is as high as $24^{\circ} \mathrm{C}$. The initial acidity of milk varies very considerably, and even in milk examined within an hour of the time of milking the quantity of acidity calculated as lactic acid may be as high as 0.1 per cent., so that, taking it generally, the work required of the preservative is to arrest the production of one-tenth per cent. of acidity calculated as lactic acid in the milk during the time which must necessarily elapse between the time of milking and the time of consumption.

As the souring of milk is due to the development of several organisms it by no means follows that the smell or taste of an unpalatable milk is measured by the amount of acidity as determined by titration. But as the coagulation of milk apparently depends upon this factor, irrespective of the nature of acidity, it seems reasonable to take it as a measure of the quality of milk. I have, however, observed slight coagulation in milk when the acidity has been as low as 0.194 per cent. of lactic acid.

Another important point to bear in mind is that a preservative is obviously more efficient if added to the milk at the time of milking so that the development of the organisms present in the milk is retarded from the very commencement, and this points to the conclusion that the legitimate use of preservatives should be restricted to its use by the farmer or cowkeeper and not by the middleman or vendor or consumer. It is urged by some that the consumer could preserve his milk if he thought it was necessary, but without entering into a discussion of Dr. M. K. Robinson's case, and dismissing for the moment Dr. O. Liebreich's reply to it, which in my opinion seems clearly to establish that the poisoning was not due to boric acid, such a method of dealing with the problem would open the way to future cases similar to that of Dr. Robinson in which excessive doses of preservatives might be taken by susceptible individuals.

It may not be generally known to readers of THE LANCET that in the case of butter the loss of flavour and the beginning of rancidity are very carefully gauged by experts, so that points or marks of value are assigned to butters whicb give their commercial value. In the report for the Nen Zealand Department of Agriculture for $1898 \mathrm{Mr}$. Sorensen shows that butter containing 3 per cent. of salt and $\frac{1}{2}$ per cent. of boric acid and subjected to cold storage yields on keeping a butter baving the greatest number of points, 37 out of 45 , whilst butters with 1 per cent. of boric acid and only 2 or 3 per cent. of salt gave an inferior result, and those containing either more or less salt without boric acid had lost still more fiavour. These results are extremely 
interesting as showing that in this particular case it is to the interest of the trader to keep the boric acid low, as from the commercial point of view the butter with $\frac{1}{2}$ per cent. of boric acid has a better flavour and will fetch a better price than that containing 1 per cent.

The last point which I wish to refer to is the value of feeding experiments in connexion with this subject. Those published by Mr. Foulerton and myself with milk containing formaldehyde were of value in establishing the fact that adult animals, notwithstanding the fact that their body weight was far less than that of man, could consume large quantities of milk preserved with moderate amounts of preservatives without apparent injurious effect. It has been pointed out by Dr. H. E. Annett and others that the cats used in these experiments were three months old, but we did not mention the fact that we had previously attempted to feed kittens three weeks old similar to those used by Dr. Annett. These attempts, however, were unsuccessful, as we found that kittens at this age, when taken directly from their mother, were not capable of assimilating their food when the food consisted only of undiluted and unpreserved cow's milk, and six kittens died under our hands. I attribute this partly to the fact that cow's milk is an unfit food for these young kittens, as it is well known that the characteristic of cat's milk is a very large percentage, amounting to 6 per cent., of albumin, a constituent which is only present in cow's milk to the extent of about $\frac{1}{2}$ per cent., so that such food is as unsuitable for young kittens as undiluted cow's milk is for infants. It will be noticed in Dr. Annett's experiments that in these young kittens the results were very irregular, and that whereas the normal rate of increase per week should be from 30 to 40 grammes, or roughly 10 per cent. of the body weight, in kittens receiving untreated milk in some cases he actually obtained decrease in weight and in others only an increase of two or three grammes. The heavier and older the kittens the more reliable are the results. Another significant point in Dr. Annett's experiments is that the larger quantity of preservative-viz., 80 grains per gallon-did not seem so fatal as the milk containing balf this amount, as it will be noticed that with the smaller quantity of preservative he obtained two deaths out of five in the third week, whereas with the larger quantity all of the animals survived this time. Similar irregular results were obtained by him with the milk containing formaldehyde, as he obtained three deaths with the weaker solution, none with the formaldehyde of 1 in 25,000, and two with the stronger solution. Before these experiments of Dr. Annett were published I had carried out a few feeding experiments with kittens about five weeks old, at which age they can take cow's milk freely, but I restricted the quantity to about 70 cubic centimetres per animal per day and used the preservative in the proportions already advocated, so that each kitten received about half a grain of boric acid per day. The results are summarised as follows :-

TABLE III.

\begin{tabular}{|c|c|c|c|c|c|c|}
\hline & \multirow{2}{*}{\multicolumn{2}{|c|}{-}} & \multicolumn{4}{|c|}{$\begin{array}{c}\text { Average weight in grammes of animal } \\
\text { fed on- }\end{array}$} \\
\hline & & & Milk. & $\begin{array}{l}\text { Milk + } \\
\text { formal- } \\
\text { dehyde. }\end{array}$ & $\underset{\text { (I) }}{\text { Milk }}+$ & $\begin{array}{l}\text { c acid. } \\
\text { (2) }\end{array}$ \\
\hline First week & $\ldots \quad \ldots$ & $\ldots \quad \ldots$ & 517 & 591 & 595 & 630 \\
\hline Second week & $\ldots \quad \ldots$ & $\ldots \quad \ldots$ & 537 & 657 & 646 & 664 \\
\hline Third week & $\ldots \quad \ldots$ & $\ldots \quad \ldots$ & 610 & 674 & 684 & $744^{*}$ \\
\hline
\end{tabular}

Percentage increase in weight on first week.

\begin{tabular}{lllll|r|r|r|r} 
Third week & $\ldots$ & $\ldots$ & $\ldots$ & $\ldots$ & 18.00 & $14 \cdot 1$ & 15.6 & 5.4 \\
& & & & & & & 15.0 & 18.1
\end{tabular}

* In the third week this kitten was fed on formalised milk instead of on borated milk.

Making allowance for the difference between different animals and the irregularities always noticed in animal experiments, the natural increase cannot be said to be interfered with. All were active and healthy at the conclusion of the experiment. As pointed out by Dr. Liebreich we have in Dr. Annett's experiments no information given us as to the quantity of milk supplied to the kittens, and it is quite possible that they received a much larger quantity of preservative than the above. As a kitten weighs approximately one pound and $I$ gave mine half a grain of boric acid per day, it would follow that a child six months old, weighing $12 \mathrm{lb}$., could take, therefore, six grains of boric acid a day, or, say, a pint and a half of preserved milk. If any value, therefore, is to be attached to animal experiments, the relation of body weight to the amount of preservative exhibited must be taken into account. Of course, this relation is recognised in the Pharmacopoeia, but it is well known that the usual allowance for doses for children of some drugs does not obey any definite law. In the Pharmacopoeia this quantity of six grains of boric acid per day for a child six months old would be about eight times the medicinal dose. I am, therefore, inclined to agree with Mr. Foulerton that experiments on animals have, after all, but a very slight bearing upon the problem under investigation. As Dr. Liebreich points out, even regarding Dr. Annett's experiments in their most favourable light they by no means prove that boric acid and formaldehyde are poisonous for young children, even in quantities largely in excess of those which would be possible in a milk diet when the preservatives were regulated in the way suggested.

Victoria-street, S.W.

\section{MYOIDEMA IN PULMONARY TUBER- CULOSIS.}

By HUGH WALSHAM, M.A., M.D. CANTAB., M.R.C.P. LOND.,

ASSISTANT PHYSICIAY TO THE OITY OF LONDON HOSPITAX FOR DISEASES OF THE CHEST.

IF in an advanced case of pulmonary tuberculosis a point on the chest wall corresponding to the clavicular origin of the pectoralis major be sharply struck with the tip of the forefinger the phenomenon usually known as "myoidema" will probably be produced. Myoidema may be divided into two varieties-viz., the fascicular and the nodular. The fascicular variety is the one most easily produced. At the point which is struck a sulcus is formed which quickly travels to the origin and insertion of the muscle, where it is lost. In the nodular variety there is formed at the point struck a small quivering tumour which, after oscillating backwards and forwards, as if uncertain of its position, for a second or two, finally comes to rest and after a few seconds gradually fades away. If the point struck be carefully watched the initial pallor produced by the blow quickly gives way to redness, reminding one forcibly of the tache cérébrale. This redness of the skin remains for a considerable time, occasionally for ten minutes or even longer, before it finally disappears. Both the fascicular and nodular variety may be obtained in other muscles besides the great pectoral. It is very commonly found in the deltoids and scapular muscles, especially in the infra-spinatis. After the tumour has faded away it may again be produced by another tap on the muscle, not necessarily in the same spot but near it. The phenomenon can be produced a third or even a fourth time, but not afterwards, the muscle apparently becoming fatigued and refusing to contract to the stimulus.

The phenomenon of myoidema is nothing new. The condition was described long ago by Dr. Stokes ${ }^{1}$ of Dublin, but not under its present name. Dr. Stokes's words are as follows: "There is another highly interesting circumstance connected with percussion which we do not think has as yet been described. Some time ago on percussing a patient who had laboured under a pectoral affection with several symptoms indicative of tubercular development we were surprised to observe that after each stroke of the ends of the fingers a number of little tumours appeared answering exactly to the number and situation of the points of the fingers where they had struck the integuments of the chest. These having continued visible for a few moments subsided, but could be again made to appear on repeating the per. cussion." The term " myoidema" was first made use of by a surgeon, the late $\mathrm{Mr}$. Lawson Tait", who wrote a monograph on the subject. He considered the sign to be

\footnotetext{
1 Dublin Hospital Reports, vol. $v_{\text {., }}$ p. 70
} 